\title{
HASIL BELAJAR MATEMATIKA MATERI BIDANG DATAR MENGGUNAKAN MEDIA PEMBELAJARAN CABRI II D
}

\author{
Purni Munah Hartuti ${ }^{1}$, Rini Widia Putri $Z^{2}$ \\ Program Studi Teknik Informatika, Universitas Indraprasta PGRI ${ }^{1,2}$ \\ Email: purniibunyahanum@yahoo.co.id ${ }^{1}$
}

\begin{abstract}
Abstrak
Pentingnya inovasi dalam pembelajaran menjadi salah satu kunci untuk meningkatkan hasil belajar matematika siswa. Salah satu bentuk inovasi dalam pembelajaran matematika adalah dengan menggunakan Cabri II D untuk materi bidang datar. Cabri II D adalah sebuah software interaktif untuk pembelajaran geometri guna mengkonstruksi gambar, sama seperti apa yang bisa dilakukan oleh penggaris, jangka dan busur sehingga hasilnya dapat lebih akurat. Tujuan penelitian ini adalah untuk mengetahui perbedaan hasil belajar matematika materi bidang datar menggunakan media pembelajaran Cabri II D dan media konvensional. Metode penelitian menggunakan metode eksperimen. Penelitian ini dilakukan di SMP PGRI 1 Cibinong dengan sampel kelas 7.2 sebanyak 40 siswa sebagai kelompok eksperimen dan kelas 7.1 sebanyak 40 siswa sebagai kelompok kontrol. Pada kelas eksperimen, diterapkan pembelajaran matematika materi bidang datar menggunakan media Cabri II D, pada kelas kontrol diterapkan pembelajaran matematika materi bidang datar menggunakan media penggaris, jangka dan busur. Pada akhir pemberian materi, diberikan tes akhir matematika materi bidang datar pada masing-masing kelas. Hasil penelitian menunjukkan terdapat perbedaan rata-rata hasil belajar siswa antara kelompok eksperimen dan kelompok kontrol. Nilai akhir siswa yang mengunakan media pembelajaran Cabri II D lebih tinggi secara signifikan daripada siswa yang menggunakan media pembelajaran konvensional.
\end{abstract}

Kata Kunci : hasil belajar matematika, bidang datar, Cabri II D

\begin{abstract}
The importance of innovations in learning is one of the keys to improving student mathematic's learning outcome. One of the innovations in learning mathematics is to use Cabri II D for plane geometry. Cabri II D is an interactive software for learning geometry to construct a drawing, like a ruler, calipers, and protractor so that the results can be more accurate. The research objective was to determine the differences in learning outcome of mathematic's plane geometry using Cabri II D learning media and conventional media. The research method used experimental methods. This research was conducted at SMP PGRI 1 Cibinong with a sample of class 7 consisting of 40 students as the experimental group and class 7.1 consisting of 40 students as the control group. In the experimental class, learning plane geometry was using Cabri II D media, in the control class, learning plane geometry was using ruler, calipers, and protractor. At the end of the topic, a final mathematical test of plane geometry was given in each class. The results showed that there were differences in the average student learning outcome between the experimental group and the control group. The final score of students using Cabri II D learning media was higher than students who used conventional learning media.
\end{abstract}

Key Words : mathematic's learning result, plane geometry, Cabri II D

\section{PENDAHULUAN}

Matematika merupakan mata pelajaran wajib yang diberikan dari tingkat pendidikan dasar hingga pendidikan tinggi. Pentingnya mempelajari matematika karena menjadi dasar ilmu-ilmu yang lain serta penerapannya ada dalam kehidupan sehari-hari. Hal ini sesuai dengan pendapat yang dikemukakan [1] bahwa "We can find mathematical application in the nature, technology, architecture, machinery, building industry, in the banking sector, in research, cartography etc". Manfaat lainnya belajar matematika menurut [2] adalah "dengan mempelajari matematika dapat membentuk pola berfikir yang logis, 
analitis, sistematis, kritis, kreatif, serta kemampuan bekerja sama". Sedangkan pola pikir siswa itu dapat dilatih dengan memfasilitasi siswa mengembangkan daya pikirnya.

Di sinilah letak peran guru dalam memfasilitasi siswa agar mampu mengasah pola pikir siswa memahami matematika secara baik. Menurut [3] salah satu faktor keberhasilan peserta didik adalah guru yang mampu merancang pembelajaran, menumbuhkan motivasi, serta menciptakan pembelajaran yang menarik. Banyak cara yang dapat ditempuh guru untuk meningkatkan kemampuan pemahaman siswanya terhadap materi matematika, salah satunya dengan menggunakan media pembelajaran. Menurut [4] "One of the factors that determine the success of mathematics learning is the learning media used. Learning media can help students to create mathematical abstract mathematics that is abstract". Pentingnya media pembelajaran dalam matematika menurut [5] karena tidak semua materi dapat dicerna siswa hanya melalui penjelasan verbal oleh guru. Siswa perlu melihat objek nyata dalam membangun ide-ide dan konsep-konsep matematikanya.

Seiring berkembangnya teknologi, media pembelajaran juga telah banyak mengalami kemajuan. Salah satunya dengan adanya media pembelajaran berbasis komputer. [6] mengatakan "Penggunaan media pembelajaran berbantu komputer mempunyai pengaruh yang signifikan terhadap daya tarik siswa untuk mempelajari kompetensi yang diajarkan." Menurut [7] "Dalam pembelajaran, guru yang menggunakan teknologi dapat mempercepat, mempermudah, dan memperlancar proses perencanaan, pelaksanaan, dan evaluasi dalam pembelajaran“. Dengan memanfaatkan teknologi inilah guru dapat berinovasi dalam pembelajaran. Sesuai pendapat [8]
"Teacher Is The Main Person In Helping Learners To Have Access To Technology Capabilities. The Teacher Should Have Necessary Expertise, Content And Learning Activities Management and Try To Change His/her Class From A Static To A Dynamic Status".

Penggunaan komputer sebagai media pembelajaran matematika di antaranya dengan mengoperasikan berbagai software pendukung pembelajaran matematika. Salah satu software yang dapat digunakan adalah Cabri II D. Software ini secara khusus untuk mempelajari geometri bidang datar. Pentingnya menggunakan software dalam pembelajaran geometri menurut [9] adalah "The dynamic nature of dynamic geometry software provides students to learn geometric concepts and to explore and visualize geometric relationships easily". Dedeuglo dalam [10] mengatakan One of the most important softwares providing such opportunities is the dynamic geometry software, Cabri $2 d$. This software is among the dynamic geometry softwares used worldwide. Cabri $2 d$ software is built on Euclidean geometry. In Cabri 2d, objects can be intuitively constructed by the user after being selected using the mouse.

Cabri II D merupakan perangkat terpenting yang bersifat dinamis. Membantu siswa dalam membangun objek geometri secara intuitif, mengeksplorasi dan memvisualisasikan hubungan geometris dengan mudah untuk memahami konsep geometris.

Penyajian materi bangun datar akan lebih menarik bagi siswa karena dapat membantu siswa mengenali, menganalisis, dan mengkonstruksi bangun datar secara mandiri. Sejalan dengan pendapat [11] menyatakan Studying geometry is an important component of learning mathematics because it allows students to 
analyse and interpret the world they live in as well as equip them with tools they can apply in other areas of mathematics. Therefore, students need to develop an understanding of geometric concepts as well as gaining adequate geometry related skills. In this project, analyses the development of geometric skills and the use of tools, reproduction of constructions, properties verification, conjecture and research.

Selain itu [12] menyatakan "We concur and argue that supporting learning of geometric concepts and spatial reasoning should be a priority moving forward for the study of children's literature in mathematics learning". Sesuai dengan pentingnya dukungan penanaman konsep geometri untuk literasi siswa dalam pembelajaran matematika.

Berdasarkan hasil survei dan wawancara dengan guru mata pelajaran matematika di SMP PGRI 1 Cibinong, pembelajaran untuk materi bidang datar belum memanfaatkan teknologi sebagai media pembelajaran. Biasanya, guru hanya menggunakan penggaris, jangka, atau busur untuk melukis bangun datar. Salah satu kekurangan media manual ini adalah tidak hemat waktu. Jam pelajaran akan habis hanya untuk mempraktikan cara melukis bangun datar, sehingga kekurangan waktu untuk membahas dan mengerjakan soal latihan. Pentingnya penggunaan Cabri II D di SMP PGRI 1 Cibinong dalam pembelajaran adalah untuk meningkatkan hasil belajar matematika siswa khususnya materi bidang datar. Hasil belajar menunjukkan sebuah prestasi, menurut [13] dapat terjadi jika adanya perubahan pemahaman, dari yang belum bisa melakukan sesuatu dan menjadi bisa dan kecenderungan sebuah perubahan kearah positif. Sedangkan menurut [5] hasil belajar merupakan perubahan yang diperoleh siswa setelah melakukan serangkaian proses belajar.

Tujuan dari penelitian ini adalah untuk mengetahui perbedaan hasil belajar matematika materi bidang datar dengan media pembelajaran Cabri II D dan media pembelajaran konvensional. Manfaat dari penelitian ini bagi guru matematika SMP PGRI 1 Cibinong di antaranya dapat mengenal dan menggunakan software Cabri II D untuk pembelajaran bidang datar serta menarik minat siswa dalam belajar. Sedangkan untuk para siswa dapat meningkatkan pemahaman dan mengubah aktivitas pembelajaran yang tidak membosankan.

\section{METODE}

Penelitian ini dilaksanakan di SMP PGRI 1 Cibinong. Populasi adalah semua siswa kelas 7 dan sampel penelitian adalah 7.2 sebagai kelompok eksperimen dan kelas 7.1 sebagai kelompok kontrol. Ada beberapa pertimbangan yang menjadikan peneliti memilih objek dan lokasi penelitian tersebut adalah: di sekolah tersebut belum memanfaatkan fasilitas sekolah yang sudah ada seperti LCD dan sekolah belum memanfaatkan software aplikasi yang ada.

Variabel penelitian yang diajukan oleh peneliti untuk melakukan studi ilmiah ini di antaranya adalah: Media Pembelajaran Cabri II D, Media Pembelajaran Konvensional dan Hasil Belajar Matematika Materi Bidang Datar. Teknik penelitian yang digunakan dalam penelitian ini adalah pendekatan kuantitatif dengan media eksperimen. Jenis perlakuan diberikan pada dua kelas belajar siswa yang berbeda. Kelas yang satu dijadikan sebagai kelompok eksperimen yaitu diberikan perlakuan (treatment) Media Pembelajaran Cabri II D. Sedangkan kelas lainnya sebagai kelompok kontrol dengan perlakuan (treatment) media pembelajaran 
konvensional. Perlakuan terhadap variabelvariabel yang diteliti yaitu Media Pembelajaran Cabri II D, Media Pembelajaran Konvensional.

Dalam penelitian ini teknik pengumpulan data yang digunakan oleh peneliti di antaranya adalah observasi langsung. Pengumpulan data observasi dilakukan dengan mengumpulkan data dari kedua media pembelajaran yaitu Media Pembelajaran Cabri II D dan konvensional. Serta memberikan tes akhir setelah selesai materi bidang datar. Sesuai dengan tujuan penelitian ini, teknik analisis data yang digunakan adalah Uji- $t$ untuk dua kelompok data dari dua kelompok sampel (tidak berpasangan)

\section{HASIL DAN PEMBAHASAN}

Tabel 1. Deskripsi Data Penelitian Media Pembelajaran Cabri II D

\begin{tabular}{|c|c|c|}
\hline$N$ & $\begin{array}{l}\text { Valid } \\
\text { Missing }\end{array}$ & $\begin{array}{l}40 \\
40 \\
\end{array}$ \\
\hline$M e$ & & 8,0788 \\
\hline \multicolumn{2}{|c|}{ Std. Error of Mean } & ,11699 \\
\hline \multicolumn{2}{|c|}{ Median } & 8,0000 \\
\hline \multicolumn{2}{|c|}{ Mode } & $7,25^{\mathrm{a}}$ \\
\hline \multicolumn{2}{|c|}{ Std. Deviation } & ,73988 \\
\hline \multicolumn{2}{|c|}{ Variance } &, 547 \\
\hline \multicolumn{2}{|c|}{ Range } & 2,80 \\
\hline \multicolumn{2}{|c|}{ Minimum } & 7,00 \\
\hline \multicolumn{2}{|c|}{ мaximum } & 9,80 \\
\hline \multicolumn{2}{|c|}{ Sum } & 323,15 \\
\hline
\end{tabular}

Tabel 2. Deskripsi Data Penelitian Media Pembelajaran Konvensional

\begin{tabular}{ll}
\hline$N$ & \multicolumn{1}{c}{ Valid } \\
Missing & 40 \\
Mean & 70 \\
Std. Error of Mean &, 11609 \\
Median & 7,7500 \\
Mode & 7,75 \\
Std. Deviation &, 73424 \\
Variance &, 539 \\
Range & 3,25 \\
Minimum & 6,00 \\
Maximum & 9,25 \\
Sum & 302,00 \\
\hline
\end{tabular}

Jumlah responden kelompok eksperimen sebanyak 40 siswa dengan nilai minimum 7.0, nilai maksimum 9.80, rata-rata 8.0788, Median 8.000, Modus 7.25, simpangan baku 0.73988 , varians 0.547 .

Jumlah responden kelompok kontrol sebanyak 40 siswa dengan nilai minimum 6.0, nilai maksimum 9.25, rata-rata 7.5500, Median 7.750, Modus 7.75 simpangan baku 0.73424 , varians 0.539 .

Tabel 3. Uji Normalitas One-Sample Kolmogorov-Smirnov Test

\begin{tabular}{lll}
\multicolumn{3}{c}{ One-Sample Kolmogorov-Smirnov Test } \\
\hline Normal Parameters ${ }^{a, b}$ & Y & 80 \\
& Mean & 7,8144 \\
& Std. &, 77921 \\
& Deviation & \\
Most Extreme Differences & Absolute &, 095 \\
& Positive &, 095 \\
& Negative &,- 072 \\
Test Statistic &, 095 \\
Asymp. Sig. (2-tailed) &, $069^{\mathrm{c}}$ \\
\hline a. Test distribution is Normal. & \\
b. Calculated from data. & \\
c. Lilliefors Significance Correction.
\end{tabular}

Pengujian hipotesis pada penelitian ini dengan menggunakan Uji- $t$ untuk dua kelompok data dari dua kelompok sampel (tidak berpasangan) terlebih dahulu dilakukan uji persyaratan analisis data yaitu uji normalitas dan uji homogenitas. Hasil pengujian normalitas menunjukkan bahwa semua kelompok data yang diuji normalitasnya dengan uji KolmogorvSmirnov dengan SPSS 22 memberikan nilai signifikansi 0.200 untuk data Hasil Belajar Matematika Materi Bidang Datar Dasar dengan Media Pembelajaran Cabri II D, 0.200 untuk Hasil Belajar Matematika Materi Bidang Datar Dasar dengan media konvensional yang berarti $>0,05$. Dengan demikian disimpulkan bahwa 2 kelompok data dalam penelitian ini berasal dari populasi yang berdistribusi normal. Hal ini menunjukkan bahwa salah satu prasyarat uji $F$ dalam penelitian telah terpenuhi. Untuk pengujian Normalitas Galat, hasil 
uji normalitas galat diperoleh nilai sig. = $0.069>0,05$ sehingga seluruh data dinyatakan normal galat.

\section{Tabel 4. Uji Homogenitas}

\begin{tabular}{llll}
\hline $\begin{array}{l}\text { Levene } \\
\text { Statistic }\end{array}$ & $d f 1$ & $d f 2$ & Sig. \\
\hline, 000 & 1 & 78 &, 993 \\
\hline
\end{tabular}

Untuk pengujian homogenitas varians menggunakan uji levenu's yaitu untuk mengetahui apakah data penelitian yang telah dikumpulkan berasal dari populasi yang homogen dengan taraf signifikasi $\alpha=$ 0,05 .

Dari hasil uji homogenitas antara Media Pembelajaran Cabri II Ddan media pembelajaran konvensional diperoleh nilai sig. $=0,993>0,05$ sehingga kedua data dikatakan homogen.

Tabel 5. Group Statistics pada Uji Independent Sample T-Test

\begin{tabular}{llllll}
\hline & & & & $\begin{array}{l}\text { Std. } \\
\text { Deviation }\end{array}$ & $\begin{array}{l}\text { Std. Error } \\
\text { Mean }\end{array}$ \\
\hline$Y$ & 1 & 40 & 8,0788 &, 73988 &, 11699 \\
& 2 & 40 & 7,5500 &, 73424 &, 11609 \\
\hline
\end{tabular}

Berdasarkan data hasil belajar kelompok eksperimen sebanyak 40 siswa nilai ratarata sebesar 8,0788 sementara kelompok control sebesar 7,5500. Dengan demikian secara deskriptif statistik dapat disimpulkan ada perbedaan rata-rata hasil belajar siswa untuk kelompok eksperimen dan kontrol.

Tabel 6. Uji Independent Sample T-Test

\begin{tabular}{|c|c|c|c|c|c|c|c|c|c|c|}
\hline & \multicolumn{2}{|c|}{$\begin{array}{l}\text { Levene's Test } \\
\text { for Equality } \\
\text { of Variances }\end{array}$} & \multicolumn{7}{|c|}{ t-test for Equality of Means } \\
\hline & & \multirow[t]{2}{*}{$F$} & \multirow[t]{2}{*}{ Sig. } & \multirow[t]{2}{*}{$t$} & \multirow[t]{2}{*}{$d f$} & \multirow[t]{2}{*}{$\begin{array}{l}\text { Sig. } \\
(2- \\
\text { tailed })\end{array}$} & \multirow[t]{2}{*}{$\begin{array}{c}\text { Mean } \\
\text { Difference }\end{array}$} & \multirow{2}{*}{$\begin{array}{c}\text { Std. } \\
\text { Error } \\
\text { Differen } \\
\text { ce }\end{array}$} & \multicolumn{2}{|c|}{$\begin{array}{c}95 \% \text { Confidence } \\
\text { Interval of the } \\
\text { Difference }\end{array}$} \\
\hline & & & & & & & & & Lower & Upper \\
\hline$Y$ & $\begin{array}{c}\text { Equal variances } \\
\text { assumed }\end{array}$ &, 000 & ,993 & 3,208 & 78 & ,002 &, 52875 &, 16481 & ,20063 &, 85687 \\
\hline & $\begin{array}{c}\text { Equal variances not } \\
\text { assumed }\end{array}$ & & & 3,208 & 77,995 & ,002 &, 52875 & ,16481 & ,20063 & ,85687 \\
\hline
\end{tabular}

Berdasarkan Independent Samples Test pada bagian "Equal variances assumed" diketahui nilai sig.(2-tailed) sebesar 0,002< 0,05 , maka dapat disimpulkan bahwa ada perbedaan yang signifikan (nyata) antara rata-rata hasil belajar kelompok eksperimem dan kelompok kontrol.

Pada "Mead Difference" adalah sebesar 0,52875 . Nilai ini menunjukkan selisih ratarata siswa yang diajarkan dengan media Cabri II D dan yang diajarkan dengan media konvensional atau 8,0788$7.5500=0,52875$. Dan selisih perbedaan tersebut adalah 0,20063-0,85687 (95\% Confidence Interval of the Difference Lower Upper). $t$ hitung sebesar 3,208 $>t$ tabel sebesar 1,994 maka dapat disimpulkan $\mathrm{H}_{0}$ ditolak dan $\mathrm{H}_{1}$ diterima yang berarti terdapat perbedaan rata-rata hasil belajar siswa antara kelompok Eksperimen dan kelompok kontrol. Nilai akhir siswa yang diajarkan mengunakan media pembelajaran Cabri II D lebih tinggi secara signifikan daripada siswa yang diajarkan menggunakan media pembelajaran konvensional. Pemilihan metode dan media pembelajaran akan menentukan keberhasilan guru dalam proses pembelajaran di kelas.

Penggunaan media pembelajaran dapat mempengaruhi motivasi, komunikasi dan interaksi belajar siswa untuk lebih 
merespon dan interaktif dalam kegiatan pembelajaran di kelas [14]. Dalam hal ini media pembelajaran Cabri II D terbukti cukup efektif dapat meningkatkan hasil belajar daripada media pembelajaran konvensional.

\section{SIMPULAN}

Berdasarkan penelitian yang telah dilakukan, maka dapat disimpulkan terdapat perbedaan rata-rata hasil belajar siswa antara kelompok eksperimen dan kontrol dibuktikan dengan hasil belajar kelompok eksperimen sebanyak 40 siswa dengan nilai rata-rata sebesar 8,0788 sementara kelompok kontrol sebesar 7,5500. Nilai akhir siswa yang diajarkan mengunakan media pembelajaran Cabri II D lebih tinggi secara signifikan daripada siswa yang diajarkan menggunakan media konvensional dibuktikan dengan terdapat selisih perbedaan sebesar 0,52875. Dalam hal ini inovasi media pembelajaran menggunakan software cabri II D untuk materi bidang datar layak untuk dapat dikembangkan supaya dapat meningkatkan hasil belajar matematika siswa.

\section{DAFTAR PUSTAKA}

[1] J. Hodaňová and D. Nocar. "Mathematics Importance in Our Life". INTED2016 Proc., vol. 1, no. March, pp. 3086-3092, 2016.

[2] H. R. Robert Edy Sudarwan. J. Ris. Pendidik. Mat., vol. 4, no. 1, pp. 78 86, 2017.

[3] I. Ayuwanti. "Meningkatkan Aktivitas dan Hasil Belajar Matematika Menggunakan Model Pembelajaran Kooperatif Tipe Group Investigation di SMK Tuma'ninah Yasin Metro". SAP (Susunan Artik. Pendidikan), vol. 1, no. 2, pp. 105114, 2017.

[4] S. Widodo and Wahyudin. "Selection of Learning Media Mathematics for Junior School Students". Turkish Online J. Educ. Technol. - TOJET, vol. 17, no. 1, pp. 154-160, 2018.

[5] A. Muin dan R. M. Ulfah. "Meningkatkan Hasil Belajar Matematika Siswa dengan Pembelajaran Menggunakan Aplikasi Moodle". Pythagoras, vol. 7, no. 1, 2012.

[6] D. Darmawan. “済無No Title No Title". J. Chem. Inf. Model., vol. 53, no. 9, pp. 1689-1699, 2019.

[7] N. Khuzaini dan R. H. Santosa. "Pengembangan Multimedia Pembelajaran Trigonometri Menggunakan Adobe Flash Cs3 Untuk Siswa Sma”. J. Ris. Pendidik. Mat., vol. 3, no. 1, p. 88, 2016.

[8] F. Mahini, Z. J.-A. Forushan, and F. Haghani. "The Importance of Teacher's Role in Technology-Based Education". Procedia - Soc. Behav. Sci., vol. 46, pp. 1614-1618, 2012.

[9] T. Kösa and F. Karakuş. "Using Dynamic Geometry Software Cabri 3D for Teaching Analytic Geometry". Procedia - Soc. Behav. Sci., vol. 2, no. 2, pp. 1385-1389, 2010.

[10] C. Yildiz, B. Güven, and T. Koparan. "Use of Cabri 2D Software in Drawing Height, Perpendicular Bisector and Diagonal". Procedia Soc. Behav. Sci., vol. 2, no. 2, pp. 2040-2045, 2010.

[11] A. Özerem. "Misconceptions in Geometry and Suggested Solutions". Int. J. New Trends Arts, Sport. Sci. Educ.-, vol. 1, no. 4, pp. 23-35, 2012.

[12] L. M. Flevares and J. R. Schiff. "Learning Mathematics in Two Dimensions: A review and Look Ahead at Teaching and Learning Early Childhood Mathematics with Children's Literature". Front. Psychol., vol. 5, no. MAY, pp. 1-12, 2014.

[13] M. Kamaluddin. "Pengaruh Motivasi Belajar terhadap Prestasi Belajar Matematika dan Strategi untuk Meningkatkannya". Semin. Mat. dan 
Pendidik. Mat., pp. 455-460, 2017.

[14] I.D. Lestari. "Peranan Guru dalam Pengunaan Media Pembelajaran Berbasis Information and Communication Technology (ICT) di SDN RRI Cisalak". Jurnal SAP Vol. 3 No. 2, pp. 137-142, 2018. 